\title{
ScienceDirect
}

Procedia Manufacturing 38 (2019) 1121-1129

Procedia MANUFACTURING

WWw.elsevier.com/locate/procedia

29th International Conference on Flexible Automation and Intelligent Manufacturing (FAIM2019), June 24-28, 2019, Limerick, Ireland.

\section{Influence of the natural additive on natural fiber reinforced thermoplastic composite}

\author{
D. K. Selvaraj, F. J. G. Silva*, R. D. S. G. Campilho, A. Baptista, G. F. L. Pinto \\ ISEP - School of Engineering, Polytechnic of Porto, Rua Dr. António Bernardino de Almeida, 431, 4200-072 Porto, Portugal
}

\begin{abstract}
Composite materials have a wide range of application in various domains. The fact behind using composite materials is that they give the same almost strength as metal parts in presenting lesser weight. However, the plastic parts are non-biodegradable, and they lead to the polluted environment during the disposal after end-of-life of a particular part. Nowadays natural and easily recyclable composites were preferred due to environmental concerns. The major disadvantage of using natural fibre composites is that they have low strength compared to conventional glass or carbon reinforced composite. To enhance the strength of Natural-FiberReinforced Plastics (NFRP) various techniques have been followed (Chemical treatment of the fibre, post-curing of the composites, sandwiching the composite, adding additives/fillers to the matrix) based on the feasibility and application of the composites. Among those techniques, adding additives to the matrix is one of the simple and effective ways to enhance the properties of the composite. A natural additive is developed in concern to the environmental impact of the composite. Two different types of the composite laminate were manufactured. One is with additive and one is without the additive. It is necessary to validate the strength of the composite with and without the additives by mechanical testing. Thus, tensile, flexural and moisture absorption tests were performed to verify the mechanical property enhancement achieved due to the use of additives. These tests help in characterizing the material to specific applications. The composite with the natural additive showed better mechanical properties. However, the moisture absorption tendency of the composite is increased as well, mainly due to the presence of additives on the surface of the composite along with the matrix.
\end{abstract}

(C) 2019 The Authors. Published by Elsevier B.V.

This is an open access article under the CC BY-NC-ND license (http://creativecommons.org/licenses/by-nc-nd/4.0/)

Peer-review under responsibility of the scientific committee of the Flexible Automation and Intelligent Manufacturing 2019 (FAIM 2019)

Keywords: Natural fibre reinforced composites, Natural additives, Mechanical testing, Characterization of material, Sustainability.

\footnotetext{
* Corresponding author. Tel.: +351 228340500; fax: +351 228321159.

E-mail address: fgs@isep.ipp.pt
} 


\section{Introduction}

The composite materials are replacing metals in various applications due to their tailored properties and suitability for easy adaptability to the advanced requirements, which is difficult to achieve through a single material or alloy [12]. A composite material consists of two phases with varying physical or chemical properties that, once combined, form an utterly different material: one or more than one discontinuous phase encapsulated in a continuous phase. The discontinuous phase, which is called a reinforcement, is usually harder and stronger than the continuous phase called the matrix phase. The matrix is usually more ductile, and binders the dispersed phase, sharing the load with it. One of these three basic material types (polymers, metals or ceramics) is chosen as a matrix. The dispersed phase improves the overall mechanical property of the composite and carries most of the applied load [3-4]. Nowadays, there is a considerable increase in sales volume and application of polymeric composites due to its high strength to weight ratio, excellent corrosion resistance, easy processing, and colourization, as well as an easy assembly using several joining processes [5-6]. One of the most common families of polymer matrix composite materials is the Natural-FiberReinforced Plastics (NFRP), used as the basis for this work.

An additive is defined as a substance, which is incorporated into plastics to attain a desired technical effect in the final product and is intended to be an essential part of the final product. The additives for the polymers are mainly found in two states, either solid or liquid. The solid additives can be seen in the form of powders, flakes, emulsions, granulates and beads [7]. The additive can be added to the polymer matrix at different stages of polymer processing: during polymer production, during the preparation stage of the matrix before reacting with a dispersed phase of the composite, or during the processing of finished polymer pallets. In some cases, additives can also be applied on the surface of the final product [8]. Some additives are added during the manufacturing of raw materials, which is called stabilization additives, where some high-performance additives are added during the compounding stage of the polymer. For special applications, reactive additives are chemically bound to the polymeric structure using a reactive compounding technique [9].

Additives added to a material helps in improving the properties in one or more directions, such as durability, strength, impact, thermal and flexural resistance, and wear, acoustic insulation, among others. The increase in demand for plastic products among the industries and consumers shows that these products are becoming more performing. This evolution results in needing high service temperature, high dynamic, high mechanical strength, high chemical, and radiation resistant odourless products [10-11]. Additives are not only making the resin processable but also help in improving the properties of the part during its life. In recent years, the range of additives has increased a lot and has an extremely complex chemical structure as well. However, not all these additives are suitable for all the materials. Most of the commercial additives are made of single compounds, but there are some cases where additives are a mixture of many compounds or oligomeric [9].

Fibres are hair-like materials that are a continuous thread or discrete elongated pieces, while there are two types of fibres: natural fibres and human-made or synthetic fibres. Natural fibres come from plants, which include coir, jute, basalt, cotton, banana, bamboo, hemp, and so on. These fibres are eco-friendly, lightweight, renewable, cheap and bio-degradable. These fibres are used to reinforce both thermosetting and thermoplastic matrices [12]. Natural fibre composites are attractive to industry because of their low density and environmental advantages over conventional composites. These are gaining importance due to their non-carcinogenic and biodegradable properties. Natural fibre composites are cost-effective materials in building and construction, packaging, automobile, railway coach interiors, and storage devices. These composites act as a replacement of high-cost glass fibre for low load bearing applications [13-14]. All plant fibres, either from wood or non-wood origin, are composed of three main cell wall polymers such as cellulose, lignin and matrix polysaccharides (such as pectin and hemicellulose) associated with cellulose and lignin in the cell wall. A high percentage of cellulose in the fibre correlates positively with desirable characteristics. The main disadvantages of natural fibres are low strength compared to man-made fibres and high moisture absorption tendency, which can be altered by chemical treatment [15-16] or by adding additives/fillers to the composite [17-18].

Researchers across the globe are developing new composites containing both natural and synthetic additives, termed it as hybrid composites. The impact and the compressive properties of these hybrid composites are bettercompared mono-additive or no-additive composites [19-20]. Ameri et al. [21] characterized and optimized the Unidirectional (UD) flax/epoxy composite by introducing paper as an additive reinforcement. In comparison with UD flax/paper/epoxy composite showed better strength and modulus compared to UD flax/epoxy composite and it 
improved specific stiffness with a decrease in specific strength compared to UD glass/epoxy composite. Couture et al. [22] conducted a similar study by replacing epoxy with PLA sheets and used a thermal forming technique to manufacture the composite. The specific tensile strength achieved by flax/PLA/paper configuration is $217 \mathrm{MPa} \mathrm{cm} / \mathrm{g}$

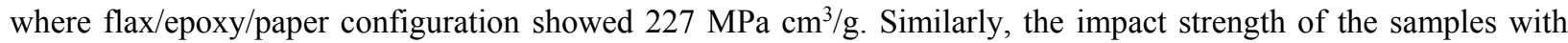
paper $(600 \mathrm{~J} / \mathrm{m})$ reinforced resin was higher than the unreinforced resin $(15 \mathrm{~J} / \mathrm{m})$ which clearly indicates that the paper as additive improves the mechanical property of the composite. Prasad et al. [23] studied the physical and mechanical behaviour of composite materials with natural fillers and concluded that the natural additives decrease the tensile strength of the polyester composite when the impact strength is increased with increase in additive content. Similarly, the moisture absorption capacity also increases with an increase in the additive content in the composite. Dhanola et al. [18] evaluated the influence of natural fillers on the mechanical properties of the luffa/polyester composite. The tensile $(31.5 \mathrm{MPa})$ and the impact strength $(9 \mathrm{~J})$ of the composite of filler loaded composite are high compared to unfilled composite where the moisture absorption also increases with the filler content [24].

\section{Materials and Methods}

This section describes the method of fabrication of the composite and the tests performed to characterize the material. To characterize the material and evaluate the impact of the additive on the material, two different composite laminates were produced. One was with the presence of Tamarind Seed Powder (TSP) additive and another was without TSP additive. The laminates were prepared using Vacuum Aided Resin Transfer Molding (VARTM) technique, which is an advanced composite manufacturing method that allows much higher quality product than the hand lay-up process, less manufacturing costs compared to the Resin Transfer Molding (RTM) and the autoclave method and it is one of the effective and efficient methods to produce composite parts with low cost [25].

Mechanical testing was performed to characterize the material and study in deep the composite. In characterizing the new material, the sample size of the specimen and its geometry are principal factors since they have an influence on the properties during tensile and bending tests. There are some different standards available from ASTM or ISO. In this study, the tensile and bending tests were performed on two different samples of sets with reference to ASTM D3039 [26] for tensile properties and ASTM D2344 [27] for bending properties. The study on moisture absorption tendency of the composite is important since it is an NFRP composite. That tendency is studied by conducting tests with reference to ASTM D5229 [28] specifications. These methods are more suitable for Fiber-Reinforced Plastics (FRP) composites in general and different sample sizes were used according to the test and needed setup.

\subsection{Materials specification}

This section is to describe the materials used in the fabrication of this composite and its properties. The materials used in this study are biaxial flax natural fibre, Elium ${ }^{\circledR}$ liquid thermoplastic resin, and TSP natural additive.

The fibre used here is a natural fibre named flax, which is an annual crop grows in the cold climatic region, especially in northern Europe. The fibres are extracted by pulling out the whole plant once the flowers are bloomed and the retting process is carried out to produce lengthy line fibres. The fibre is used in a form of biaxial (-45/45) fabric which provides an advantage of distributing more strength in two directions along its length. The matrix material here is Elium ${ }^{\circledR}$ liquid thermoplastic resin, which is manufactured by Arkema, a French company. Elium ${ }^{\circledR}$ stays liquid at room temperature and the hardening process is triggered by peroxides in general. The usage of liquid thermoplastic resin will ease the recycling process of the composite. The additive or the filler materials are fine powder made of Tamarind, a tropical fruit seed. This additive acts as a void filler or a compacting material and helps in improving the stiffness of the material. The mechanical and physical properties of the fiber and the Elium ${ }^{\circledR}$ resin can be seen in Table 1 and Table 2, respectively.

The TSP additive is a powder from tamarind seeds. The preparation of the additive is a simple and straightforward process. The seeds are removed from the fruit and then washed with clean water to get rid of the waxy layer present around it. The cleaned seeds are then dried under the sunlight to get rid of the moisture. The dried seeds are inspected to get rid of the foul seeds then it is ground using a flour mill to get a fine powder. The texture of the powder might play a significant role in the strength of the material but for this study, a fine powder is prepared and used. The density 
of the powder is calculated approximately by tightly filling a known volume container, weighed in a highly precision weighing scale and it is found to be $290-310 \mathrm{~kg} / \mathrm{m}^{3}$ without considering the air voids present inside.

Table 1. Mechanical and physical properties of fibre [29].

\begin{tabular}{lccc}
\hline \multicolumn{4}{l}{ Mechanical and physical properties of Fiber } \\
\hline Properties & Test Methods & Value & Units \\
\hline Density & ASTM 1577 & 1500 & $\mathrm{~kg} / \mathrm{m}^{3}$ \\
Thread diameter & - & 20 & $\hat{A} \mu \mathrm{u}$ \\
Tensile Strength & ASTM C1557 & 500 & $\mathrm{MPa}$ \\
Tensile Modulus & ASTM C1557 & 50 & $\mathrm{GPa}$ \\
Strain & - & 2 & $\%$ \\
\hline
\end{tabular}

Table 2. Mechanical and physical properties of Elium ${ }^{\circledR}$ resin [30].

\begin{tabular}{|c|c|c|c|}
\hline \multicolumn{4}{|c|}{ Mechanical and physical properties of Elium ${ }^{\circledR}$ Resin } \\
\hline Properties & Test Methods & Value & Units \\
\hline Density (Before Curing) & ISO 1675 & 1010 & $\mathrm{~kg} / \mathrm{m}^{3}$ \\
\hline Viscosity (Before curing) & - & 100 & m.Pas \\
\hline Tensile Strength & ISO 178 & 66 & $\mathrm{MPa}$ \\
\hline Tensile Modulus & ISO 178 & 3.17 & $\mathrm{GPa}$ \\
\hline Flexural Strength & ISO 527 & 111 & $\mathrm{MPa}$ \\
\hline Flexural Modulus & ISO 527 & 2.19 & $\mathrm{MPa}$ \\
\hline Shore D hardness & ISO 868 & $85-90$ & - \\
\hline Coeff of linear Expansion & ISO $2155-1$ & 0.065 & $\mathrm{Mm} / \mathrm{m} /{ }^{\circ} \mathrm{C}$ \\
\hline
\end{tabular}

\subsection{Manufacturing of the composite}

The composite laminate is manufactured using a VARTM process, which comprised of a simple circuit of equipment and tools. The manufacturing process follows basic steps such as laying the fibre layers on the mould and setting up the vacuum chamber and so on. The schematic setup of the VARTM process can be seen in Fig. 1 (a). Two different laminates are produced one is without additive and another is with TSP additive of 5\% of the weight of the matrix used in the system. The natural additives may vary from 5 to $15 \%$ of the weight of the matrix material and it will be the optimum range according to [18]. The setup of the manufacturing process and the produced laminates can be seen in Fig.1 (a), (b) and Error! Reference source not found. (c), (d) respectively.

(a)

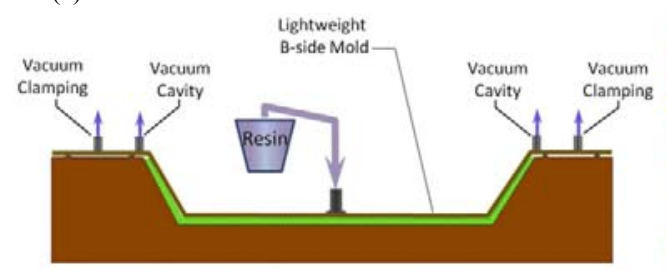

(b)

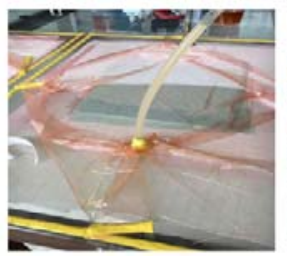

(c)

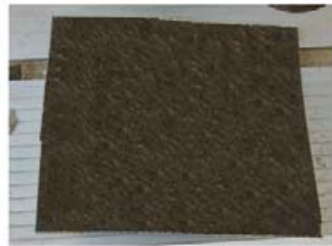

(d)

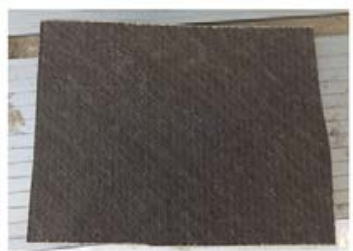

Fig. 1. (a) VARTM Schematic representation; (b) VARTM Process; (c) Manufactured laminates without Additive; (d) Manufactured laminates with additive.

\subsection{Material characterization}

\subsubsection{Tensile test}

The tensile test is one of the primary tests which must be done while characterizing a new material. In tensile testing, the samples are prepared according to ASTM D3039 standard ( $250 \times 25 \times 4$ [mm]) and pulled along the length of the sample using a universal testing machine. A biaxial extensometer is attached to the sample to measure the displacement along the length and width of the sample. By measuring the displacement and the force applied, stressstrain is calculated across the specimen and stress vs strain curve is plotted. The elastic modulus or Young's modulus of the material can be determined by taking slope along the elastic zone of the plotted curve. 
The tensile test is performed using a Shimadzu $100 \mathrm{kN}$ load cell universal testing machine and the test parameters can be found in Table 3. Sixteen coupons from two different samples were made and used for testing.

Table 3. Tensile test specification of flax/Elium ${ }^{\circledR}$ composite.

\begin{tabular}{llll}
\hline \multicolumn{3}{l}{ Specimen Characteristics } & Test Parameters \\
\hline Material & Flax/Elium ${ }^{\circledR}$ Composite & Test velocity $[\mathbf{m m} / \mathbf{m i n}]$ & 1.00 \\
Specimen geometry & Rectangular & Wedge distance $[\mathbf{m m}]$ & 150 \\
Test condition & $24^{\circ} \mathrm{C}$ & Gauge length $[\mathbf{m m}]$ & 25 \\
Test Standard & ASTM D3039 & Test Equipment & The LVDT $100 \mathrm{kN} \mathrm{load} \mathrm{cell}$ \\
\hline
\end{tabular}

\subsubsection{Bending test}

The three-point bending test measures the force needed to bend a beam under three-point loading conditions. The data is often used to select materials for parts that will support loads without flexing. Flexural modulus is used as a sign of a material's stiffness when flexed. The parameters for this test are the support span, the speed of the loading, and the greatest deflection for the test. Flexural strength, also known as modulus of rupture, bend strength, or fracture strength as a mechanical parameter for brittle material, is defined as a material's ability to resist deformation under load. Most commonly the specimen lies on a support span and the load is applied to the centre by the loading nose producing three-point bending at a specified rate. To characterize the polymer matrix composite, shot beam bending test is the best method to standardize the beam strength and the mode of failure.

Bending tests were performed using a Shimadzu $100 \mathrm{kN}$ load cell universal testing machine and the test parameters can be found in Table 4. The test is performed according to ASTM D2344 standard and the three coupons each form two different samples were prepared with the dimension on $40 \times 12 \times 5$ [mm]. The bending test specifications can be seen in Table 4.

Table 4. Bending test specification of Flax/Elium ${ }^{\circledR}$ Composite.

\begin{tabular}{llll}
\hline \multicolumn{2}{l}{ Specimen Characteristics } & Test Parameters & \\
\hline Material & Flax/Elium ${ }^{\circledR}$ Composite & Test velocity $[\mathbf{m m} / \mathbf{m i n}]$ & 1.00 \\
Specimen geometry & Rectangular & Wedge distance $[\mathbf{m m}]$ & 17.7 \\
Test condition & $24^{\circ} \mathrm{C}$ & Test Equipment & The LVDT $100 \mathrm{kN}$ load cell \\
Test Standard & ASTM D2344 & & \\
\hline
\end{tabular}

\subsubsection{Moisture absorption test}

In characterizing an NFRP composite it is important to study the moisture absorption tendency of the material. Since a natural additive is also added to the composite which has the tendency to absorb moisture by nature this test helps in studying and standardizing the material characteristics. Moisture Absorption of Matrix Composites (ASTM D5229) is a gravimetric test method that monitors change over time of moisture content by measuring the total mass change of a coupon that is exposed to a specified environment. The composite is subjected to extreme condition testing compared to its intended application in this case. The specimens are placed in an atmosphere of $85^{\circ} \mathrm{C}$ at $90 \%$ humidity over a period of 120 hours. The coupons are weighted to know the initial weight and then for every 24 hours to figure out the absorbed moisture content. The average change in mass is seen, which is necessary to conclude the absorbed mass in total. The mass loss and the average effective moisture equilibrium is calculated by using Equation 1 and Equation 2.

$$
\begin{aligned}
& \text { Mass lost, } \%=\frac{W_{a b}-W_{p}}{W_{a b}} * 100 \\
& E W E=\left|M_{i}-M_{i-1}\right|<0.020 \%
\end{aligned}
$$

Where $\mathrm{Wab}$ is the initial weight, $\mathrm{Wp}$ is the current weight, $\mathrm{M}$ is the average moisture content, I is the value at the current time, i-1 = value at a previous time, and EWE- effective moisture equilibrium change. 


\section{RESULTS AND DISCUSSION}

\subsection{Tensile tests}

The tensile testing is carried on two distinct sets of coupons, one is with additives and one is without additives. The specimens with additives are represented using the name (AT) where the specimens without additive are simply denoted as (T) where AT stands for the Additive tensile specimens.

Fig. 2 shows the stress $v s$ strain curves for the T specimens, whereas Fig.3 shows the Stress $v s$ Strain curve forms tensile testing AT specimens. From the curves, it can clearly see that the ultimate tensile strength of the AT specimen is higher than that of the $T$ specimens and the strain rate is comparatively lower. The specimens may exhibit ductile behaviour, taking into account the values obtained in the tests, whereas FRP preponderantly presents a brittle behaviour. The ductility behaviour is due to the thermoplastic matrix materials and the presence of the TSP additive acting as a filler element. Similarly, the elastic zone area on the AT stress-strain curve is larger than that of the elastic zone area in T-curves. This implies that the AT specimen present high elastic modulus. The mechanical property of those two different samples can be seen in Table .

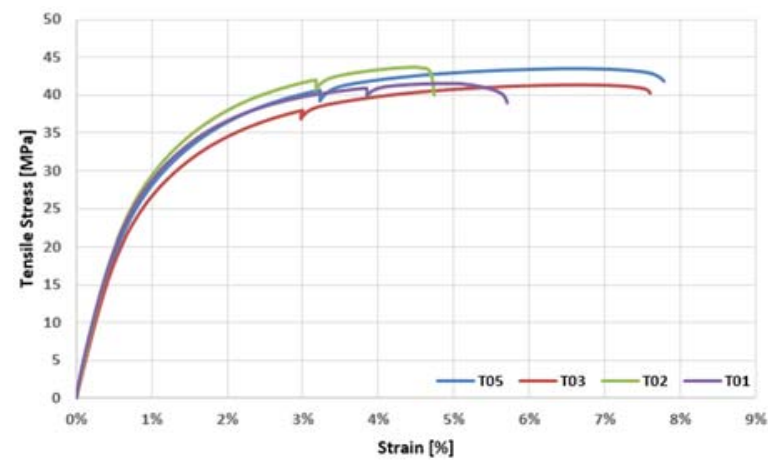

Fig. 2. Stress $v s$ Strain curve from tensile testing (T specimens).

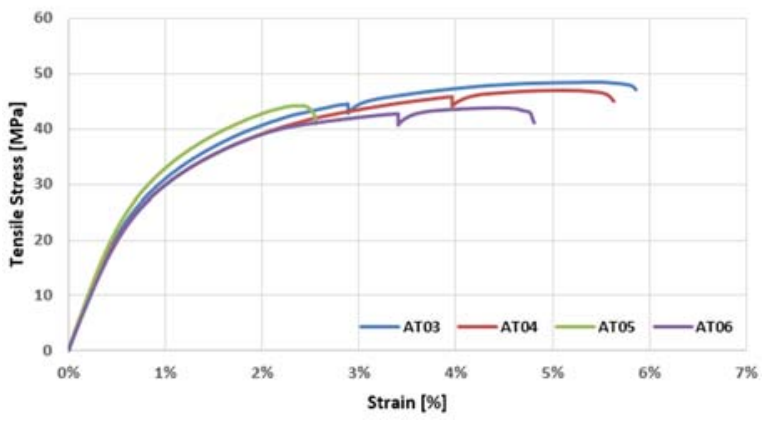

Fig. 3. Stress vs Strain curve from tensile testing (AT specimens).

Table 5. Results from the tensile test.

\begin{tabular}{|c|c|c|c|c|c|c|c|c|c|c|c|c|}
\hline \multirow[b]{2}{*}{ Mat } & \multicolumn{2}{|c|}{$\begin{array}{l}\text { Maximum } \\
\text { Force }[k N]\end{array}$} & \multicolumn{2}{|c|}{$\begin{array}{c}\text { Yield Strength } \\
\text { [MPa] }\end{array}$} & \multicolumn{2}{|c|}{$\begin{array}{c}\text { Ultimate tensile } \\
\text { stress [MPa] }\end{array}$} & \multicolumn{2}{|c|}{$\begin{array}{c}\text { Maximum strain } \\
{[\%]}\end{array}$} & \multicolumn{2}{|c|}{$\begin{array}{c}\text { Elastic Modulus } \\
\text { [GPa] }\end{array}$} & \multicolumn{2}{|c|}{$\begin{array}{c}\text { Poisson } \\
\text { Coeff }\end{array}$} \\
\hline & $\mathbf{T}$ & AT & $\mathbf{T}$ & AT & $\mathbf{T}$ & AT & $\mathbf{T}$ & AT & $\mathbf{T}$ & $\mathbf{A T}$ & $\mathbf{T}$ & AT \\
\hline Avg & 4.02 & 4.42 & 25.99 & 28.41 & 42.56 & 45.86 & 5.61 & 4.33 & 3.95 & 4.35 & 0.54 & 0.56 \\
\hline Std dev & 0.05 & 0.24 & 0.95 & 0.36 & 1.08 & 1.94 & & & 0.13 & 0.22 & 0.01 & 0.01 \\
\hline $\begin{array}{l}\text { Difference } \\
\%\end{array}$ & & & & & & & & & & & & \\
\hline
\end{tabular}

From the tensile testing, the additive influences the strength of the specimen. The average E of the specimen 'AT' is $4.35 \mathrm{GPa}$ while the $\mathrm{E}$ of sample $\mathrm{T}$ is around $3.95 \mathrm{GPa}$ which is a marginal difference. Thus, 'TSP' plays a significant role in this composite's strength. The added additive helped in enhancing Young's modulus of the composite remarkably by $10 \%$ and the ultimate Tensile of the material is also increased by $6 \%$. The Poisson's ratio of the composite is over 0.5 , which is due to the anisotropic laminate construction. For a laminate with a particular $+/$ - theta construction (no zero plies), the transverse contraction can be high due to individual ply rotation. The plies may also expand in the thickness direction, conserving laminate volume, producing an auxetic (negative Poisson's ratio) material in this direction. If the $\pm 45^{\circ}$ laminate is loaded in this direction, then the resin easily stretches and shifts, such that the fibres rotate and the transverse strain is also remarkably high and, in fact, is about $55 \%$ of the axial strain. 


\subsection{Bending tests}

This test was performed to study both the beam strength and standard failure mode during bending. Usually, in composite materials, the common mode or the obvious mode of failure during flexural loading is an inter-laminar shear failure or failure due to flexural tension. Like the tensile testing, while characterizing the specimens with the additives, they showed better strength over the specimens without the additive. In fact, here the beam strength is increased by 7\%, which is a significant improvement in FRP materials due to the addition of an additive or a filler material. From Fig. 4 it can be seen that the specimens with the additive material tend to deform less and carry more load at the same time. The specimen with additive deforms $12.5 \%$ less than the specimens without additive on average. Here, the nomenclature $\mathrm{A}$ and $\mathrm{AB}$ is used to represent the bending test samples without additives and the bending test samples with additives, respectively. The common mode of failure seen in both specimen types is inter-laminar shear/flexural tension. In this type of material, the failure is dominated by resin and interlaminate properties of the laminate. Therefore, after testing these samples the primary mode of failure in this composite was the inter-laminar shear failure.

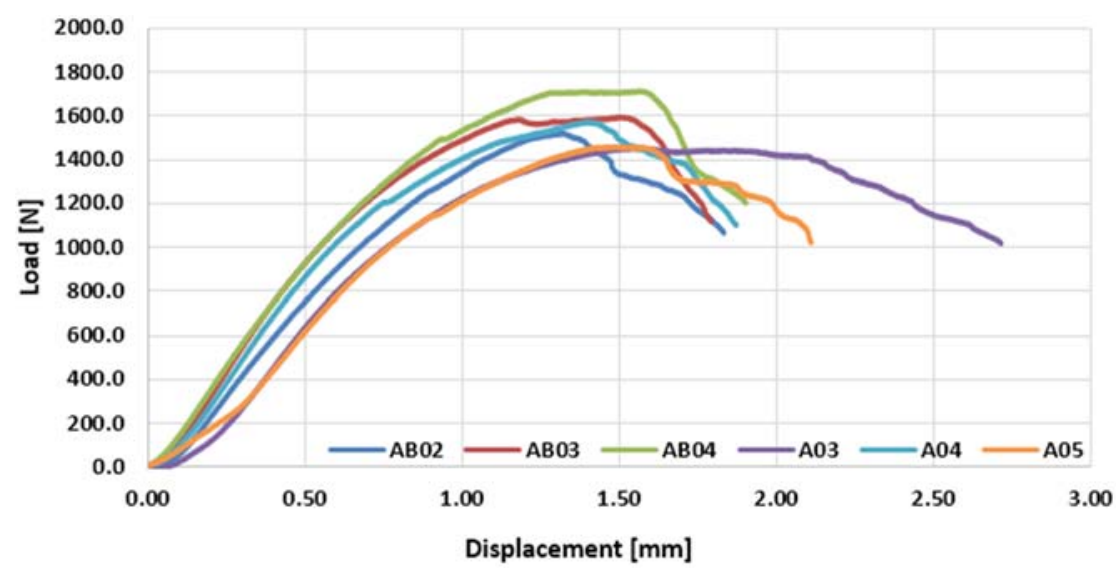

Fig. 4. Force vs Displacement curve for bending test.

\subsection{Moisture absorption test}

The Moisture absorption tendency of the material is studied according to the ASTM D5229 to characterize the water absorption tendency. As previously mentioned, the fibre is a natural material, as well as the additive, and the natural materials, in general, have the tendency to absorb moisture by nature. As expected, the specimens provided with additive tend to absorb more moisture than the specimens without additive, but that percentage is considerably small. The specimens with additive have the maximum mass change of $1.44 \%$ while the specimen without additive has a mass change of $1.33 \%$. The moisture absorption of the two different specimens can be seen in Table 6 . Here, the nomenclature AW and $\mathrm{W}$ is used to represent the specimen with and without the additive, respectively.

The mass change over a period of 120 hours can be seen graphically in Fig. 5. This clearly indicates that the additive has a small impact on absorbing the moisture. 
Table 6. Results from the Moisture absorption test.

\begin{tabular}{ccccc}
\hline \multirow{2}{*}{ Days } & Specimens & $\begin{array}{c}\text { Average mass } \\
\text { Absorption (\%) }\end{array}$ & $\begin{array}{c}\text { Average Effective Moisture } \\
\text { Content (\%) }\end{array}$ & $\begin{array}{c}\text { Abs. Effective Moisture } \\
\text { Equilibrium Change (\%) }\end{array}$ \\
\hline \multirow{2}{*}{$\mathbf{1}$} & AW & 1.4432 & 1.4432 & 1.4432 \\
\cline { 2 - 5 } & W & 1.3398 & 1.3398 & 1.3398 \\
\hline \multirow{2}{*}{$\mathbf{3}$} & AW & 0.2722 & -1.1710 & 1.1710 \\
\cline { 2 - 5 } & W & 0.0849 & -1.2549 & 1.2549 \\
\hline \multirow{2}{*}{$\mathbf{4}$} & AW & 0.0474 & -0.2247 & 0.2247 \\
\hline & W & 0.0596 & -0.0253 & 0.0253 \\
\hline
\end{tabular}

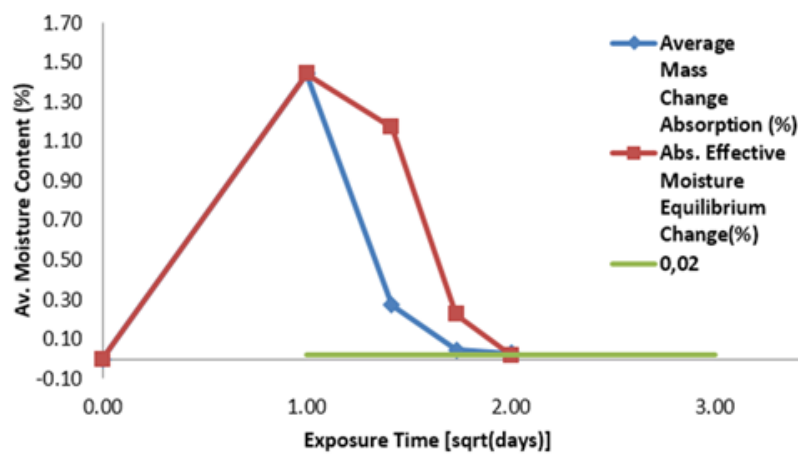

(a)

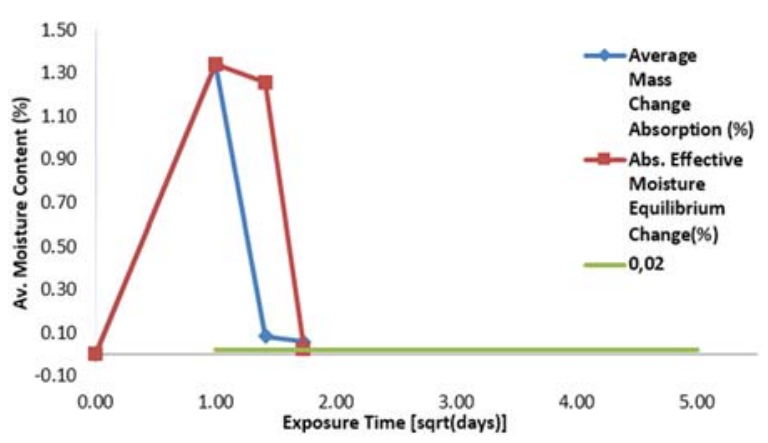

(b)

Fig. 5. Absolute Effective Moisture Equilibrium change (a) for sample AW, (b) for sample W.

\section{Conclusions}

This study was carried out to develop a new NFRP composite and a natural additive material and study the influence of that additive material in the composite. Two distinct sets of a composite laminate is manufactured by VARTM technique and as an outcome, composite laminate with a good surface finish at a needed dimension was produced, which is used to prepare the coupons. The tensile testing was carried out to characterize the material, where Young's modulus yield stress and the Poisson coefficient of the material are determined. An essential outcome of this study is that the added natural additive helps in enhancing the mechanical properties of the composite at a marginal rate, i.e., Young's modulus increased by $10 \%$ while the ultimate tensile strength increased by $6 \%$. This increase in the properties of the composite by the addition of natural additive might be a breakthrough in natural fibre composite usage. The bending test results showed that the specimens with the additive has higher beam strength and tends to carry more load with less deflection. This again clearly shows that the added additive has a strong influence on the materials. Another important outcome of this test is that all specimens have failed in an analogous way, i.e., Interlaminar shear failure. This helps in characterizing the primary failure mode of the composite under flexural loading. In contrast to the tensile and bending test results in moisture absorption testing the specimens with additive content absorb more moisture. This is due to the presence of the additive material on the surface of the specimen, which is blended with the matrix material. This causes the specimens to absorb more moisture compared to the specimens without the additive. The difference in the mass change between the two different kinds of specimens is comparatively small but, even though it must be addressed crucially. The above studies indicate that the TSP additive has a strong influence in enhancing the mechanical properties of the material by a great scale. Further studies on the additive will help in understanding and using that in a better way, for a wide range of application. In this study, a fine powder of additive was used, which opened new areas to investigate the additive by varying its particle size. To conclude this work, TSP additive will be potential filler material for FRP composites, and it is sustainable by nature. 


\section{Acknowledgements}

Andresa Baptista and Gustavo Pinto thank the financial support of CIDEM, R\&D unit funded by the FCT Portuguese Foundation for the Development of Science and Technology (Project UID/EMS/0615/2016).

\section{References}

[1]C. Colombo and L. Vergani, A micromechanical approach to evaluate the post-impact residual stiffness of woven composites, J. Compos. Material, 50 (7) (2016) 971-984.

[2] C. Ayranci and J. Carey, 2D braided composites: A review for stiffness critical applications, Composite Structures, (1) (2008) $43-58$.

[3] F. J. G. Silva, A. Baptista, G. Pinto, R. D. S. G.Campilho, M. C. S. Ribeiro, Characterization of hybrid pultruded structural products based on preforms, Composites Part B: Engineering, 140 (2018) 16-26.

[4] F. J. G. Silva, E. Amorim, A. Baptista, G. Pinto, R. D. S. G. Campilho, M. R. A. Castro, Producing hybrid pultruded structural products based on preforms, Composites Part B: Engineering 116 (2017) 325-332.

[5] M. Karus and M. Kaup, Natural Fibres in the European Automotive Industry, Journal of Industrial Hemp 7 (1) (2002) $119-131$.

[6] J. Nickel and U. Riedel, Activities in biocomposites, Materials Today, 6 (4) (2003) 44-48.

[7] M. Constantí et al., Polymer Engineering. Walter de Gruyter, Berlin, Germany, 2017. ISBN: 978-3-11-046974-5.

[8] H. Zweifel, R. D. Maier, and M. Schiller, Plastics additives handbook, Hanser Publications, USA, (2009), ISBN-13: 978-1569904305.

[9] J. C. J. Bart, Additives in polymers : industrial analysis and applications. John Wiley \& Sons, Nova Jersey, EUA, (2005), ISBN-13: 9780470850626.

[10] S. Thomas and V. P. M., Handbook of engineering and specialty thermoplastics, Volume 3: Polyethers and polyesters, Wiley-Scrivener, USA, (2011), ISBN: 978-0-470-63926-9.

[11] R. D. Deanin, Additives in Plastic, Environ. Health Perspectives, 11 (1975) 35-39.

[12] T. V. Popat and A. Y. Patil, A Review on Bamboo Fiber Composites, IRE Journals 1 (2) (2017).

[13] C. Elanchezhian, B. V. Ramnath, G. Ramakrishnan, M. Rajendrakumar, V. Naveenkumar, and M. K. Saravanakumar, Review on mechanical properties of natural fiber composites., Materials Today: Proceedings, 5 (1) (2018) 1785-1790.

[14] M. R. Bambach, Compression strength of natural fibre composite plates and sections of flax, jute and hemp, Thin-Walled Structures, 119 (2017) 103-113.

[15] R. Sepe, F. Bollino, L. Boccarusso, and F. Caputo, Influence of chemical treatments on mechanical properties of hemp fiber reinforced composites, Composite Part B Engineering, 133 (2018) 210-217.

[16] M. Sood and G. Dwivedi, Effect of fiber treatment on flexural properties of natural fiber reinforced composites: A review, Egypt. Journal Petroleum, 24 (4) (2017) 775-783.

[17] M. Bołtryk, A. Krupa, and E. Pawluczuk, Modification of the properties of the cement composites with the organic filler, Constr. Build Materials, 167 (2018) 143-153.

[18] A. Dhanola, A. S. Bisht, A. Kumar, A. Kumar, Influence of natural fillers on physico-mechanical properties of luffa cylindrica/ polyester composites, Material Today Proceedings, 5 (9) (2018) 17021-17029.

[19] A. V. Rajulu et al., Mechanical Properties of Short, Natural Fiber Hildegardia populifolia-reinforced Styrenated Polyester Composites, Journal of Reinforced Plastics and Composites, 24 (4) (2005) 423-428.

[20] K. John and S. V. Naidu, Sisal Fiber/Glass Fiber Hybrid Composites: The Impact and Compressive Properties, J. Journal of Reinforced Plastics and Composites, 23 (12) (2004) 1253-1258.

[21] E. Ameri, L. Laperrière, and G. Lebrun, Mechanical characterization and optimization of a new unidirectional flax/paper/epoxy composite, Composite Part B Engineering, 97 (2016) 282-291.

[22] A. Couture, G. Lebrun, and L. Laperrière, Mechanical properties of polylactic acid (PLA) composites reinforced with unidirectional flax and flax-paper layers, Compos. Structure, 154 (2016) 286-295.

[23] L. Prasad, G. Singh, and M. Pokhriyal, A Comparative Study on Physical and Mechanical Behaviour of Functionally Graded Composite Materials reinforced with Natural Fillers, Materials Today: Proceedings, 5 (9) (2018) 16990-16994.

[24] K.-H. Kim, J. L. Ong, and O. Okuno, The effect of filler loading and morphology on the mechanical properties of contemporary composites, Journal of Prosthetic Dentistry, 87 (6) (2002) 642-649.

[25] C. Kong, H. Lee, and H. Park, Design and manufacturing of automobile hood using natural composite structure, Composite Part B Engineering, 91 (2016) 18-26.

[26] ASTM D3039 / D3039M - 17 Standard Test Method for Tensile Properties of Polymer Matrix Composite Materials, ASTM Int., USA, (2017).

[27] ASTM D2344 / D2344M - 16 Standard Test Method for Short-Beam Strength of Polymer Matrix Composite Materials and Their Laminates, ASTM Int., (2016).

[28] ASTM D5229 / D5229M - 14 Standard Test Method for Moisture Absorption Properties and Equilibrium Conditioning of Polymer Matrix Composite Materials, ASTM Int., (2014).

[29] https://www.easycomposites.co.uk, Retrieved on 7 February 2019.

[30] Datasheet, TDS_Elium 150 Liquid Thermoplastic Resin, Paris, 2016. 